\title{
EDUCAÇÃO AMBIENTAL COMO DISCIPLINA NA FORMAÇÃO DOS BIÓLOGOS: UM ESTUDO DE CASO NA UNIVERSIDADE FEDERAL DE UBERLÂNDIA
}

\author{
Melchior José Tavares Júnior ${ }^{1}$
}

Ana Maria de Oliveira Cunha ${ }^{2}$

Resumo: O objetivo desta pesquisa foi analisar a inserção da Educação Ambiental como disciplina, no curso de Ciências Biológicas da Universidade Federal de Uberlândia (UFU), ministrada em 2009/1 e 2009/2, para entender seus limites e possibilidades na formação do biólogo. A pesquisa se propôs, ainda, analisar a influência dos parâmetros traçados em Tbilisi na proposta desenvolvida. Dentro dos parâmetros da pesquisa qualitativa, a opção foi pelo estudo de caso e realizou-se pesquisa bibliográfica, documental e de campo. A análise dos dados, subsidiada pelo referencial teórico escolhido, indicou que o oferecimento da Educação Ambiental como disciplina, embora não se constitua em uma situação ideal, consiste em um avanço para sua inserção no curso e que a disciplina atende alguns pressupostos para a Educação Ambiental acenados em Tbilisi, indo além dessas orientações sob influência de outros aportes teóricos que subsidiam as discussões na área.

Palavras-chave: Educação Ambiental. Ciências Biológicas. Estudo de Caso.

\section{ENVIRONMENTAL EDUCATION AS A DISCIPLINE IN THE TRAINING OF BIOLOGISTS: A CASE STUDY AT THE UBERLÂNDIA FEDERAL UNIVERSITY}

Abstract: The objective of this research was to analyze the insertion of environmental education as a discipline in the Biological Sciences Course of the Universidade Federal de Uberlândia (UFU), conducted in 2009/1 and 2009/2, to understand its limits and possibilities in the formation of the biologist. The research also aims to analyze the influence of the parameters outlined in the proposal developed in Tbilisi. Within the parameters of qualitative research, the option was for the case study and it was made literature search, documentary and field. Data analysis, subsidized by the theoretical referential chosen, indicated that the offer of Environmental Education as a discipline, though it doesn't constitute in an ideal situation, consists of an advance to its insertion on the course and that the course meets some assumptions for environmental education waved in Tbilisi, going beyond these guidelines under the influence of other theoretical contributions that support the discussions in the area.

Keywords: Environmental Education. Biological Sciences. Case Study.

\footnotetext{
${ }^{1}$ Doutor em Educação pela Universidade Federal de Uberlândia (UFU). Professor do curso de Ciências Biológicas da Universidade Federal de Uberlândia, Uberlândia/Minas Gerais/Brasil.

Instituto de Biologia. profmelk@hotmail.com

${ }^{2}$ Doutora em Educação pela Universidade de São Paulo (USP). Professora do Programa de Pós-Graduação em Educação/Universidade Federal de Uberlândia (PPGE/UFU), Uberlândia/Minas Gerais/Brasil. cunhaamo@gmail.com.
} 


\section{EDUCACIÓN AMBIENTAL COMO UNA DISCIPLINA EN LA FORMACIÓN DE BIÓLOGOS: UN CASO DE ESTUDIO EN LA UNIVERSIDAD FEDERAL DE UBERLÂNDIA}

Resumen: El objetivo de esta investigación fue analizar la inclusión de la educación ambiental como una disciplina en el curso de Ciencias Biológicas, en la Universidad Federal de Uberlândia (UFU), realizada en 2009/1 y 2009/2, de comprender sus límites y posibilidades en la formación del biólogo. La investigación propone, también, analizar la influencia de los parámetros señalados en Tbilisi en la propuesta desarrollada. Dentro de los parámetros de investigación cualitativa, la opción fue el estudio de caso, además de revisión de literatura, pesquisa documental y de campo. El análisis de los datos, con el apoyo del marco teórico elegido, indicó que la oferta de la educación ambiental aunque no constituye una situación ideal, consiste en un avance para su inclusión en el curso yel curso cumple con algunos presupuestos para la Educación Ambiental definidos en Tbilisi, yendo más allá de esas directrices bajo la influencia de otras aportaciones teóricas que subsidian las discusiones del área.

Palabras-llave: Educación Ambiental. Ciencias Biológicas. Estudio de caso.

\section{Introdução}

O objetivo do presente artigo é apresentar os resultados de um estudo de doutoramento desenvolvido entre 2008 e 2012, no Programa de Pós-Graduação em Educação da Universidade Federal de Uberlândia (UFU), que teve como tema a Educação Ambiental (EA), assunto com o qual nos relacionamos desde a década de 1990, quando aluno do curso de Biologia na Universidade Federal de Minas Gerais.

O contexto da pesquisa retomou nosso estudo de mestrado em educação na UFU, no qual investigamos a atenção proporcionada pelo curso de Ciências Biológicas à EA, segundo a percepção dos recém-formados. Concluído em 2005, o estudo revelou que a temática estava presente de forma incipiente e pontual no curso, sendo abordada por alunos e professores interessados no assunto, estes pertencentes à área de Práticas de Ensino. Isso acenou para a necessidade de uma disciplina obrigatória, a fim de garantir a abordagem da EA na formação dos biólogos, sob pena de concluírem o curso sem terem contato significativo com o tema.

A inclusão da disciplina de EA no currículo do curso, em 2006, foi o fato que nos conduziu ao estudo de doutorado, no qual nosso interesse foi investigar a disciplina Educação Ambiental do curso de Ciências Biológicas da UFU, ministrada em 2009/1 e 2009/2, seu primeiro ano de oferta, de modo a entender suas condições para o desenvolvimento da temática, tendo como parâmetro as orientações de Tbilisi e a discussão teórica atual a respeito. Nosso problema de pesquisa foi, portanto: quais os limites e as possibilidades da disciplina EA, inserida como obrigatória no curso de Ciências Biológicas da UFU?

\section{Caminhos metodológicos}

Para o desenvolvimento do trabalho, optamos pela pesquisa qualitativa (CHIZZOTTI, 2008; GONZAGA, 2006; LUDKE; ANDRÉ, 1986). Dentro da pesquisa qualitativa, optamos pelo estudo de caso (MARTINS, 2008; ANDRÉ, 1984), o qual vem sendo bastante utilizado, desde a década de 1990, por pesquisadores da EA (PEDRINI, 1997).

Selecionamos, assim, a referida disciplina como um caso, uma instância ou ainda uma unidade de significado (ANDRÉ, 1984), abrangendo aí os alunos, a docente responsável, as práticas disciplinares em sala e em campo, a inserção da mesma na área de Prática de Ensino, 
no Projeto Pedagógico do curso e no Instituto de Biologia da UFU. Criado desde a década de 1970, trata-se de um curso com tradição na UFU, contando com um corpo docente experiente, o que se traduz em uma das melhores graduações em Ciências Biológicas do país. É nesse contexto de excelência na pesquisa que a EA busca justificar-se como objeto de conhecimento.

Com a concordância da realização da pesquisa pela docente responsável pela disciplina, acompanhamos 110 das 144 horas-aulas ministradas durante os dois semestres de 2009, incluindo as atividades de campo municipais e intermunicipais, observando, participando e registrando-as no diário de bordo de modo descritivo e reflexivo, conforme orientam Ludke; André (1986). Nessas aulas, auxiliamos a professora em algumas atividades, participamos de algumas discussões e assumimos uma aula na ausência da mesma. Essa e outras inserções conferiram a esse estudo de caso um caráter etnográfico, conforme definido por Moreira (2002).

Para construção dos dados da pesquisa, além da pesquisa bibliográfica que nos forneceu dados teóricos, utilizamos a pesquisa documental para estudo de dados documentais. Dentre os documentos, analisamos o Projeto Pedagógico do curso, em especial a ficha da disciplina nele contida e o plano de curso da Educação Ambiental, nos dois semestres considerados. Os dados empíricos foram construídos por meio de questionários e entrevistas na pesquisa de campo.

O questionário foi aplicado a 44 dos 63 alunos matriculados nos dois semestres e teve como objetivo a busca de dados gerais sobre a disciplina, os quais foram úteis na elaboração das questões da entrevista com os 13 alunos, selecionados por sorteio, e que aceitaram ser entrevistados. A entrevista com a professora responsável pela disciplina concluiu o processo de constituição dos dados da pesquisa, os quais foram organizados na forma de categorias descritivas de acordo com Pedrini (1997) e submetidos à análise à luz dos referenciais teóricos adotados para a pesquisa.

\section{Referenciais teóricos}

Os elementos teóricos dessa pesquisa partiram dos fundamentos da EA desenvolvidos em Tbilisi (1977), os quais se revelam vigorosos até os dias atuais. Com base em autores como Goergen (2010), Loureiro (2006), Pombo (2005), Tristão (2004), Vasconcellos (2002), Leff (2001), Rhodes (1996) e Sorrentino (1995), outros elementos teóricos também foram utilizados e possibilitaram a organização dos referenciais, os quais são discutidos a seguir.

\subsection{Ciência Moderna, Pensamento Sistêmico e Educação Ambiental}

Definida na Conferência das Nações Unidas em Tbilisi (1977) como

resultado de uma reorientação e articulação de diversas disciplinas e experiências educativas que facilitam a percepção integrada do meio ambiente, tornando possível uma ação mais racional e capaz de responder às necessidades sociais", a EA discute os limites do conhecimento fragmentado da realidade e abre espaço para as possibilidades de revisão dessa forma de ver e apreender o mundo. $\mathrm{O}$ pensamento não fragmentado da realidade, qualquer que seja sua nomenclatura, não apenas caracteriza a EA, mas, também, realiza sua ancoragem no pensamento sistêmico. Para Rhodes (1996, p.29), essa ancoragem resulta da própria questão ambiental ser vista como um "ponto de viragem epistemológica". Conforme o autor, a questão ambiental colocou um aspecto até então inexistente na teoria do conhecimento:

O fato dos produtos do conhecimento disciplinar e as efetuações dele resultantes entrarem em recursividade com o próprio campo disciplinar do conhecimento. Não é uma simples ruptura bachelardiana, no sentido de um corte, uma descontinuidade ou fissura, mas uma revolução epistêmica que coloca, pela primeira vez, a necessidade do conhecimento amostrar, observar e tematizar seus próprios produtos, coisas 
(produtos concretos, físicos e industriais) e construtos (objetos conceituais, conceitos e proposições) (RHODES, 1996, p. 29-30).

O pensamento de Vasconcellos (2002) também contribui para percepção da EA nos dias atuais. A autora utiliza os pressupostos simplicidade/complexidade, estabilidade/instabilidade e objetividade/intersubjetividade para evidenciar o movimento dos cientistas de uma perspectiva fragmentada do mundo para uma abordagem integrada da realidade, conhecida como pensamento sistêmico. É a partir desse ambiente teórico que buscamos os sentidos de disciplina, currículo, especialização e interdisciplinaridade. Sobre esse conceito, Pombo (2005) afirma:

\begin{abstract}
A interdisciplinaridade não é qualquer coisa que nós tenhamos que fazer. É qualquer coisa que se está a fazer quer nós queiramos ou não. (...) Perceber a transformação epistemológica em curso é perceber que lá, onde esperávamos encontrar o simples, está o complexo, o infinitamente complexo. Que quanto mais fina é a análise, maior a complexidade que se abre à nossa frente. E, portanto, que o todo não é a soma das partes. Esta é, penso eu, uma das chaves fundamentais para o entendimento desta questão.
\end{abstract}

Recém-chegada na universidade, a EA traz consigo o desafio de ser tratada de forma interdisciplinar, que é um de seus princípios. Tarefa complexa de ser colocada em prática. Primeiramente, pelo ambiente da maioria dos cursos, estruturado nos fundamentos da Ciência Moderna e, por outro, a própria temática ainda busca uma maior densidade teóricometodológica, estando o próprio pensamento sistêmico ainda em constituição. O curso de Ciências Biológicas, como a maioria dos cursos da Universidade, se encontra consolidado teórico-metodologicamente nos moldes da Ciência Moderna.

\title{
3.2 A Biologia e a questão ambiental: implicações para a Educação Ambiental
}

Algumas características do curso de Ciências Biológicas podem ser observadas a partir dos três pressupostos do paradigma da Ciência Moderna: a estabilidade, a objetividade e a simplicidade (VASCONCELLOS, 2002, p.69), conforme citados anteriormente. Essa autora argumenta que as Ciências Biológicas, ao contrário da Física, encontraram dificuldades para encaixar-se nos fundamentos da Ciência Moderna, especialmente em relação à dimensão da estabilidade. Em relação à dimensão da objetividade, a autora afirma que "os biologicistas continuaram pensando uma natureza que, embora viva, tenha existência objetiva, independente do observador, e empenharam esforços para conhecê-la tal como é na realidade" (VASCONCELLOS, 2002, p. 95-96). Sobre a dimensão da simplicidade, a autora afirma:

\footnotetext{
É provável que o pressuposto da simplicidade tenha trazido algum desconforto para os biologicistas; entretanto, esse desconforto não os impediu de levar seu objeto para o laboratório, nem de fracionar o estudo do ser vivo, estudando separadamente, por exemplo, os sistemas digestivo, respiratório, circulatório, nervoso (VASCONCELOS, 2002, p.95).
}

Vários autores discutem o perfil do biólogo formado sob a perspectiva apresentada. Dentre esses pesquisadores, destacamos Branco (2001) e Guha (2000). Branco (2001, p.28) chama nossa atenção quanto à formação dos biólogos e a questão ambiental. Para o autor, o biólogo é formado com um "jargão específico" de sua área, e encontra-se em condição de "estranhamento" (p.12) em relação à dimensão antrópica da realidade, ao passo que, em relação à dimensão biológica da realidade encontra-se em "atribuição exclusiva" (p.12). 
Para Branco (2001), o ecossistema agora tem novo significado, passando a "metassistema" (p.74), na medida em que supera a abordagem natural. Na perspectiva desse autor, "o homem - ser vivo, espécie biológica - não pode ser visto como peça integrante do ecossistema, pois ele não possui aí um nicho ecológico definido, e o seu habitat, além de variável, integra elementos que não pertencem à natureza" (p.106). Ainda, segundo o autor:

O metassistema antrópico deixou então de possuir aquela característica que o diferenciava de todos os sistemas mecânicos, que é o de existir independente de uma finalidade preestabelecida. Ele passou a orientar-se em função dos desígnios humanos e sociais (BRANCO, 2001, p.106).

\subsection{A Educação Ambiental na Universidade}

O processo de institucionalização da EA na universidade ainda é incipiente, com a temática em fase de busca de sua identificação. Um dos seus dilemas, e ainda sem consenso mínimo, é a questão da forma de abordagem disciplinar ou interdisciplinar. (BERNARDES; PRIETO, 2010; THOMAZ; CAMARGO, 2007, BRÜGGER, 2004; TRISTÃO, 2004; SORRENTINO, 1995). Para alguns desses autores, uma disciplina de EA significa a ocorrência de uma "ilha de outra racionalidade" (BRÜGGER, 2004, p.167), um retrocesso ou mesmo uma contradição com o conceito de EA. Sobre esse posicionamento, Rodrigues (2004, p.407) é enfático:

\footnotetext{
A utilização de formas tradicionais de educação, pela criação de disciplinas específicas, para trabalhar temas transversais, tais como cidadania, direitos humanos e meio ambiente, que tem objetivo formativo e não meramente informativo, não tem dado certo.
}

Por outro lado, dentre os pesquisadores citados, também encontramos aqueles que consideram a disciplina de EA uma possibilidade viável, uma estratégia para o fortalecimento da temática na universidade.

Devido à novidade da temática, não se encontra um volume significativo de investigações sobre disciplinas de EA no ensino superior, a partir das quais se possa construir um panorama desse fenômeno e, assim, ampliar nossa interlocução. Nesse momento histórico, é possível perceber diversas iniciativas que vão desde disciplinas interdepartamentais até relatos de experiências bem sucedidas de pesquisa em EA na graduação. Por outro lado, a disciplina parece entrar e sair dos currículos sem justificativa plausível, mudando de lugar na grade curricular, ainda indefinido sobre quem é o profissional que está apto a ministrá-la. Na outra ponta, é grande o volume de pesquisas, evidenciando o resultado de uma formação cuja EA ou foi ausente ou se caracterizou por uma abordagem naturalista.

\subsection{Tendências da Educação Ambiental}

As inúmeras tipologias para a EA podem implicar em maior dificuldade para a abordagem pedagógica do tema. Para dialogar com as tendências adotadas pela disciplina investigada - Tradicional, Resolução de problemas, Integradora e Transformação Social (FERNANDES, 2002), elencamos as tipologias apresentadas no livro "Identidades da Educação Ambiental Brasileira", lançado em 2004, e que teve como objetivo identificar, explicitar e distinguir as principais tendências da EA no país a partir dos anos 90. São elas: Educação Ambiental Conservacionista; Crítica, Transformadora ou Emancipatória; Educação no Processo de Gestão Ambiental; Ecopedagogia e a Alfabetização Ecológica. Incluímos nessa sistematização uma nova tendência para a EA, os Estudos Culturais. Especificamente em 
relação a essa última tendência, note-se que a mesma pode ser importante para o desenvolvimento da EA, podendo desempenhar, conforme Lima (2010, p.92), "um papel relevante na compreensão e na interpretação dos novos e vertiginosos fenômenos socioculturais que desnorteiam as disciplinas tradicionais". Entretanto, a centralidade na categoria cultura e a recente ênfase na subjetividade e na construção das identidades podem dificultar a inserção dos Estudos Culturais no ambiente da EA brasileira, notadamente crítica. Essa é apenas uma dentre muitas outras tipologias.

Para além do panorama das tendências da EA, elencamos, também, o que Leff (2001) chamou de saber ambiental, uma iniciativa que surge com o propósito de construção de novos objetos interdisciplinares, construídos a partir do contato com a comunidade, estando, assim, muito além da interação entre as tradicionais disciplinas acadêmicas. Para esse autor, "o saber ambiental não só gera um conhecimento mais objetivo e abrangente, mas também produz novas significações sociais, novas formas de subjetividade e de posicionamento diante do mundo" (LEFF, 2001, p.239). Se, por um lado, Leff afirma que os programas de EA e os objetivos por eles propostos dependem da constituição e incorporação do saber ambiental às pesquisas e práticas docentes, por outro, afirma que a EA não pode esperar por sua constituição, sugerindo um desenvolvimento recíproco:

O processo educacional, vinculado a um processo de pesquisa e produção de conhecimentos, deve ser concebido como um laboratório de sistematização e experimentação de saberes que vão sendo inscritos nos programas de formação ambiental no próprio processo de sua constituição (LEFF, 2001, p.219).

Nesse momento histórico, a razoável institucionalização da EA no ensino superior, inclusive por vias legais, abre possibilidades para o desenvolvimento simultâneo da EA e do saber ambiental. Assim, embora a EA dependa de um saber para se organizar, a ela caberá iniciativa concreta para a constituição desse mesmo saber, um salto por sobre os muros da universidade em busca da construção de novos objetos interdisciplinares do conhecimento.

\section{Resultados e discussão}

De posse dos dados colhidos no estudo de caso, constituímos diversas categorias descritivas, as quais foram obtidas a partir da observação das aulas da disciplina durante os dois semestres de 2009, da análise do Projeto Pedagógico do Curso, do plano da disciplina, do questionário aplicado às turmas, da entrevista com alunos e com a professora responsável. As categorias obtidas são apresentadas e discutidas a seguir.

A disciplina no projeto pedagógico do curso. A inclusão da disciplina Educação Ambiental no projeto pedagógico do curso de Ciências Biológicas da UFU garantiu a presença da temática. Entretanto, sua desarticulação com as demais disciplinas sugeriu que tal inserção tenha ocorrido do mesmo modo como se insere qualquer outra disciplina. Apesar de ter sido organizado na perspectiva da multi e da interdisciplinaridade, a disciplina foi inserida em um currículo que, na prática, é disciplinar. A interdisciplinaridade deveria ser desenvolvida pelo núcleo de formação pedagógica, do qual a disciplina faz parte, porém, isso não ocorreu. Convém ressaltar que a proposta interdisciplinar não deveria se restringir às disciplinas do núcleo, mas se estender a todas as disciplinas do curso. A forma disciplinar, que acabou prevalecendo no atual projeto pedagógico do curso, implicou em uma limitação para a EA, uma contradição a um de seus princípios básicos, que é a compreensão abrangente da realidade a ser atingida pelo enfoque interdisciplinar. Assim, a inserção da EA na forma disciplinar contraria o princípio da interdisciplinaridade da temática, desenvolvido desde a Conferência de Tbilisi 
(1977) e, depois, reafirmado em 1992, no Tratado de Educação Ambiental para Sociedades Sustentáveis e Responsabilidade Global (TEASS), quais sejam:

Aplicar um enfoque interdisciplinar, aproveitando o conteúdo específico de cada disciplina, de modo que se adquira uma perspectiva global e equilibrada; A Educação Ambiental deve envolver uma perspectiva holística, enfocando a relação entre o ser humano, a natureza e o universo de forma interdisciplinar (SATO, 2003, p.18).

No momento em que caberia à universidade preparar os professores para atuarem na escola pública com formas alternativas à abordagem disciplinar da EA, a inclusão da EA como disciplina na formação inicial pode delegar esse papel à formação continuada, o que nos remete a Pombo (2005, p.12), que afirma:

Se a universidade não é apenas uma escola, a verdade é que ela também é uma escola e, enquanto escola, ela tem que preparar para a interdisciplinaridade. Ela tem que perceber as transformações epistemológicas em curso e, de alguma maneira, ir ao seu encontro.

A presença da disciplina no curso. A presença da disciplina foi muito valorizada pelos alunos, os quais reconheceram a importância da temática para sua formação, como se observa no seguinte depoimento:

Eu acho muito importante. Se não tivesse essa disciplina a gente talvez não teria essa visão mais profunda de Educação Ambiental, de como trabalhá-la tanto na Educação Básica como no Ensino Médio, como passá-la para outras pessoas mesmo. Eu acho muito importante, fundamental (E3).

A valorização da disciplina pelos alunos remete a uma semelhança daquilo que encontramos na pesquisa de mestrado. Naquele momento, a reivindicação dos alunos por uma disciplina de EA sugeria um interesse pela temática, porém não havia como afirmar que tal interesse existia de fato, pois não havia a disciplina. Na situação atual, com a presença da disciplina, o interesse dos alunos se revelou legítimo, o que deve chamar a atenção do curso para a importância da temática na formação dos alunos, podendo ser monitorado pela ocorrência do tema na pesquisa, no ensino e na extensão.

Sobre a abordagem interdisciplinar da EA, a professora responsável considerou um imperativo, mas ressaltou a dificuldade para o seu exercício, mesmo entre os próprios professores da área de Práticas de Ensino do curso, que ministram a disciplina Projeto Integrado de Prática Educativa (PIPE), que foi criado para ser interdisciplinar:

A ideia do PIPE é superinteressante, mas desde que os professores que trabalhassem PIPE tivessem essa visão, mas não temos professores nessa visão não disciplinar. Eu até tenho essa visão, mas com quem vou contar, se nem nos próprios PIPES que seriam a integração das disciplinas do semestre a interdisciplinaridade não acontece! Ninguém conversa, não há conversa entre esses professores. O professor de determinada disciplina não conhece o que é dado na outra, como que ele se integra pra dar o próprio PIPE, que seria o que acontece nessas disciplinas na educação. Que é válido é, pode ser que um dia a gente chegue a isso (Professora entrevistada).

O depoimento da docente evidenciou a dificuldade para o trabalho interdisciplinar. Apesar do projeto do curso ter sido organizado com uma estrutura multi e interdisciplinar, objetivando preparar o egresso para atuar por essas perspectivas, especialmente pela atuação do núcleo de formação pedagógica, o que se observou foi que os professores não conseguiram, ainda, cumpri-lo, o que nos remete a Tristão (2004, p.77), quando afirma que "o/a professor/a 
universitário/a em sua maioria ainda é resistente à mudança que a dinâmica do conhecimento exige nesse início de século". Para Verdi e Pereira (2006), a dificuldade para o trabalho interdisciplinar resulta da ausência dessa abordagem no processo formativo dos professores.

Apesar da dificuldade apontada, a docente considerou que a forma disciplinar da EA não significa um isolamento da temática no curso; antes, oferece subsídios para ações em EA. A importância que a docente atribuiu à presença da disciplina, considerando-a como estratégica para o desenvolvimento da temática no contexto atual do curso, nos remete à tese de doutorado de Sorrentino (1995), na qual o autor percebeu a disciplina como um lugar onde os interessados em EA podem se encontrar.

Nesse mesmo sentido, compreendemos que a forma disciplinar da EA, nesse momento histórico da universidade, ainda caracterizado pela fragmentação do conhecimento, revelou-se como uma importante estratégia para fortalecimento da temática no referido curso.

A carga horária e a localização da disciplina na grade curricular. Considerada suficiente pela professora e pela maioria dos alunos, a carga horária da disciplina deve permanecer em 60 horas. Essa duração acompanhou o perfil de quase $70 \%$ das 38 disciplinas de EA em cursos de graduação no país, conforme mapeamento realizado pela Rede Universitária de Programas de Educação Ambiental (RUPEA), em 2005. Entretanto, note-se que a formatação da EA nessa carga horária parece refletir mais a tradição dos currículos acadêmicos modernos do que o resultado de pesquisas que apontem uma carga horária compatível com as particularidades da temática e as condições para que seus objetivos sejam atingidos na formação inicial. Foi o caso deste estudo, pois argumentamos que, apesar de a disciplina ter sido considerada satisfatória por alunos e professora, as 60 horas se revelaram insuficientes para dar conta tanto dos aspectos teóricos, que se mostraram muito complexos, quanto dos aspectos práticos da EA, os quais exigem maior tempo e disponibilidade dos alunos.

O dilema sobre a localização da disciplina na grade curricular chamou a atenção para além da questão imaturidade/maturidade dos alunos em relação ao aproveitamento da temática. Trata-se da discussão sobre a forma ou as formas de abordagem da temática em um curso de graduação, de que modelos se pretende utilizar para a afirmação da interdisciplinaridade da EA (TBILISI, 1977).

A disciplina e as concepções dos alunos sobre Educação Ambiental. A atividade da Dinâmica do Diamante, para sondar as concepções sobre EA entre os alunos, foi muito interessante, embora os alunos pareçam ter tido dificuldade em interpretar as frases contidas nas fichas. A presença marcante da tendência Tradicional de EA entre os alunos, revelada na aplicação desse instrumento se manteve após o término da disciplina, o que não era esperado. Como o objetivo da disciplina era o alargamento da visão dos alunos, esperava-se que as outras tendências: Resolução de problemas, Integradora e Transformação Social se tornassem mais expressivas entre os estudantes. Quando perguntados sobre qual foi a influência da disciplina na elaboração de sua concepção, os alunos afirmaram coerentemente que a disciplina chamou a atenção para a EA, um conceito que é muito amplo e que ainda está em construção. O pouco alargamento da visão dos alunos em relação à concepção de EA chama a atenção para a complexidade do trabalho com o graduando em Ciências Biológicas (BITTAR et al., 2007), o que discuto na categoria a seguir.

Estratégias didáticas da disciplina. O estranhamento dos graduandos à dimensão antrópica, presente na disciplina, pode ser compreendido a partir do pensamento de Branco (2001), que explicita que esse estranhamento é compreensível, pois se trata de uma dimensão que não faz parte da formação do biólogo, ao contrário da dimensão biológica, com a qual ele possui familiaridade. De fato, percebemos que a disciplina investigada carrega consigo algo inesperado pelos biólogos em formação, ou seja, um conteúdo eminentemente humano, carregado pela complexidade do ser humano, evidenciado pela dimensão política dos mesmos, muito diferente da segura e exclusiva dimensão biológica (BRANCO, 2001) à que estão 
familiarizados. A identificação com a dimensão biológica também ajuda a explicar a predominância da tendência Tradicional de EA (FERNANDES, 2002) nessas turmas.

Entretanto, o estranhamento dos alunos à dimensão antrópica presente na disciplina não deve ser confundido com uma rejeição à EA, o que pode ser observado pela satisfação dos mesmos com a presença da disciplina, recomendando, inclusive, que a mesma permaneça como obrigatória no curso. Além de a disciplina ter sido bem aceita pelos alunos, sua forma de abordagem foi considerada por eles como satisfatória, o que revelou, por um lado, a capacidade da professora responsável e, por outro, a importância dessas estratégias para quem se dispuser a ministrar a disciplina. A frase a seguir exemplifica a satisfação dos alunos:

Eu gostei. Vídeos, textos, a própria disposição que a gente sentava na sala era favorável à discussão, à conversa, à apresentação de ideias. Eu gostei bastante, eu acho que os elementos utilizados para gerar, pra estimular a discussão, a apresentação dos temas a serem discutidos foi muito bem pensada, os textos, os vídeos, as imagens, eu gostei muito, não tenho nem o que sugerir (E7).

Embora a disciplina tenha sido muito valorizada pelos alunos, a reivindicação por mais atividades práticas, conforme eles, botar a mão na massa, foi quase unânime. Essa reivindicação dos alunos sugeriu uma percepção da EA como ação, reforçando o que havíamos percebido em nosso estudo de mestrado. Para a professora, essa exigência dos alunos é natural, mas seu posicionamento sobre a importância da parte teórica da EA permanece sem desvalorizar as atividades práticas. A professora valorizava a teoria por ser essa considerada importante para as questões ambientais, mas os alunos esperavam mais atividades práticas, porque queriam vivenciar a EA, possivelmente, compreendendo-a como ação, uma atitude para solução de questões ambientais.

Os Estudos Culturais na disciplina. Os Estudos Culturais foram citados pela professora como a tendência que gostaria de imprimir à disciplina, ainda que outros textos tenham sido utilizados, conferindo à disciplina um caráter eclético. Conforme suas palavras:

O objetivo maior da disciplina é um alargamento da visão. Então nesse aspecto os Estudos Culturais vão me dar mais suporte, porque alargamento é um termo muito usado nessa área. Então ela teria uma tendência maior nesse aspecto, por que valorizo essa abordagem (Professora entrevistada).

A influência dos Estudos Culturais nas atividades desenvolvidas teve maior visibilidade em três momentos.

O primeiro momento ocorreu no início da disciplina, quando a professora apresentou aos alunos quatro tendências da EA - Tradicional, Resolução de problemas, Integradora e Transformação Social, informando se tratar de elementos culturais híbridos para interpretação da realidade. $\mathrm{Na}$ perspectiva dos Estudos Culturais, as tendências foram explicadas pela docente como artefatos produtores de sentidos e conhecimentos que circulam e disputam significados na arena cultural (COSTA; SILVEIRA; SOMER, 2003; SAMPAIO; WORTMANN, 2004).

O segundo momento ocorreu durante a leitura de textos relacionados aos Estudos Culturais e à análise dos artefatos culturais por eles descritos e propostos. Conforme a docente relatou na entrevista, o fato de ampliar o olhar das pessoas sobre a realidade situa a atividade não apenas no âmbito cultural, mas também no âmbito político. Ao olhar para o conteúdo dos textos utilizados, observamos o interesse em compreender a produção discursiva que determinado artefato pudesse efetuar.

O terceiro momento ocorreu no final da disciplina, com o mapeamento ambiental, cuja definição é perpassada pelos aspectos culturais (MEYER, 2001). A atividade oportunizou o 
contato dos alunos com a comunidade, não tendo sido concretizado em um projeto de ação devido à necessidade de maior tempo para envolvimento das turmas com os moradores, o que reduziu o potencial dessa proposta no que diz respeito à transformação social. $\mathrm{O}$ mapeamento pode ser um importante exercício que contextualiza temáticas clássicas e isoladas como lixo, ar, água, vegetação, dentre outras, contribuindo para uma EA, como diz Reigota (2007), que aborda temáticas cada vez mais complexas, conflituosas, marcadas por múltiplas representações e interesses.

Nos três momentos discutidos, observamos que a professora responsável pela disciplina não reduziu a disciplina à abordagem dos Estudos Culturais. De nossa parte, acreditamos que os Estudos Culturais necessitam de um melhor acoplamento com a EA, a qual se ocupa da realidade como lugar, enquanto nos Estudos Culturais o lugar é ocupado pela noção de cultura e da produção discursiva que ali ocorre (COSTA; SILVEIRA; SOMER, 2003).

A disciplina e a pesquisa em Educação Ambiental. Embora os alunos matriculados na disciplina tenham sido informados de que a temática poderia ser objeto de pesquisa, essa não foi vinculada às atividades propostas. Esse fato, associado à localização da disciplina no sétimo período, dificultaram que a temática fosse objeto de investigação. Os alunos entraram em contato com a disciplina já comprometidos com a pesquisa nas diversas áreas da Biologia como Genética, Microbiologia, Ecologia, dentre outras.

Para Cunha (1998), a ausência da pesquisa na disciplina se justifica pela lógica tradicional do currículo universitário, que prevê a aprendizagem pela transmissão e não pela dúvida, o que fomentaria a atitude da pesquisa. Entretanto, a pesquisa nas disciplinas da graduação se constitui não apenas como uma tendência atual para a metodologia do Ensino Superior (MASETTO, 1998), mas também como uma das prerrogativas para uma disciplina de EA na formação inicial (BERNARDES; PRIETO, 2010). Retorno a Leff (2001, p.219), que atribui à pesquisa, um dos motores capazes de contribuir para o desenvolvimento do saber ambiental: "O processo educacional, vinculado a um processo de pesquisa e produção de conhecimentos, deve ser concebido como um laboratório de sistematização e experimentação de saberes que vão sendo inscritos nos programas de formação ambiental no próprio processo de sua constituição".

A disciplinaridade e a interdisciplinaridade da Educação Ambiental na disciplina. Apesar da temática disciplina/interdisciplina na EA não ter feito parte da programação da disciplina, a mesma se mostrou aberta ao interdisciplinar. $\mathrm{O}$ fato da professora receber um pesquisador para acompanhar a disciplina, permitindo sua participação efetiva, é um ponto para esse argumento. Para abordar o assunto, a professora entrevistada assevera que:

\begin{abstract}
A disciplina deve trabalhar essa questão. Ela deve estar no contexto da disciplina, mas não com o comprometimento de um aprofundamento teórico. Eu não me sinto à vontade para discutir profundamente essa questão. Teria que ser alguém da área da Filosofia, ou da Didática, ou da Sociologia, teria que ter um conhecimento da epistemologia mesmo, pra trabalhar com Morin ou com outros autores e eu não tenho esse aprofundamento.
\end{abstract}

Não discordando da professora, de que para discutir essa questão é preciso estar preparado teoricamente, o tema disciplinaridade/interdisciplinaridade, em qualquer programa de Educação Ambiental, é central. Sua ausência leva a uma redução do assunto aos limites da prática, em detrimento da discussão das questões epistemológicas que a fundamentam. Para o seu desenvolvimento, necessário se faz oportunizar aos alunos a discussão sobre a Ciência Moderna e a nova Ciência (VASCONCELLOS, 2002), e a EA nesses contextos.

A postura docente durante a disciplina. Destacamos o importante, comprometido e competente trabalho desenvolvido pela docente responsável pela disciplina. A experiência acumulada como professora que, desde 1995 está na instituição, atuando nos temas Ensino de 
Ciências e Biologia, Mídia e Cultura, Plantas Medicinais, EA, Etnoconhecimento dentre outros, se fez presente na elaboração e na permanente revisão da disciplina, conforme testemunhamos. Como exemplo dessas revisões, temos o plano de curso que foi cuidadosamente modificado no segundo semestre de 2009, as inserções não previstas como o filme-documentário "Homem Urso" e o texto de Umberto Eco, ou mesmo a suspensão do mapeamento ambiental como atividade a partir do terceiro semestre de oferta da disciplina. A professora entrevistada falou sobre as revisões:

Por exemplo, num semestre, eu percebo que há o interesse dos alunos por determinados assuntos ou então a discussão da sala de aula leva a incluir determinada questão. Não é fácil fazer essas escolhas, o que vai entrar e o que não vai entrar.

A disciplina aconteceu em um contexto de currículo disciplinar, com disciplinas estanques, ampliando o desafio que a professora enfrentou com profissionalismo, certa de que a oportunidade era estratégica para o fortalecimento da EA, conforme argumentação de Sorrentino (1995), sobre a opção de concordar da EA como disciplina.

As alternativas apresentadas pela professora sobre o futuro da EA na formação dos biólogos evidenciaram os desafios da temática, conforme observamos em suas palavras:

Eu penso que a Educação Ambiental não necessariamente precisa ser uma disciplina, mas eu não consigo ainda pensar em como que ela poderia acontecer. O PIPE é uma tentativa de trazer um novo jeito de organização do currículo. As duzentas horas que os alunos fazem de atividade complementar no nosso currículo também é uma maneira de flexibilizar! (Professora entrevistada).

\section{Considerações finais}

A inserção da EA como disciplina no curso de Biologia da UFU não atendeu, integralmente, o princípio da interdisciplinaridade defendida para a temática desde a conferência de Tbilisi. A estrutura disciplinar, com horários rígidos e a convencional carga horária de 60 horas, dificultou que a proposta da EA como transformação social se efetuasse, outro princípio estabelecido desde Tbilisi e reafirmado pelos autores que se dedicam a esse assunto.

A reduzida comunicação entre os próprios professores das disciplinas, inclusive os do núcleo de formação pedagógica, evidenciou o predomínio do caráter disciplinar do curso e implicou na localização da temática no sétimo período. A posição da disciplina na matriz curricular diminuiu as possibilidades da temática como objeto de pesquisa, pois os alunos, quando vão cursá-la, já estão envolvidos em outras áreas de pesquisa. Desse modo, poderia ser promissora a inserção da disciplina nos períodos iniciais do curso de Ciências Biológicas.

A abordagem da parte teórica da EA se revelou, às vezes, complexa para os futuros biólogos, que, geralmente, têm dificuldade com os textos da área de Educação, não tendo sido diferente com os textos selecionados para a disciplina que se caracterizou por enorme riqueza, qualidade e atualidade. Embora as tendências da EA adotadas representem as grandes correntes da temática no país, as frases da Dinâmica do Diamante, aplicada para levantar as concepções dos alunos, deixaram algumas dúvidas.

O estranhamento dos alunos à natureza antrópica do discurso presente na disciplina é compreensível em um curso de Biologia, no qual predomina a concepção Tradicional de EA, percebida desde o estudo de mestrado e reafirmada agora nas entrevistas realizadas. $\mathrm{O}$ desafio que se apresenta ao curso de Ciências Biológicas, pelas mãos da EA, consiste no alargamento da noção de ecossistema para metassistema, ou seja, o reconhecimento de que o homem não 
cabe no conceito de ecossistema mas que, ao mesmo tempo, precisa ser inserido nas investigações sobre o ambiente natural, levando-se em consideração seus atributos humanos. Tal alargamento pode possibilitar a discussão dos paradigmas da modernidade, quais sejam a estabilidade, a objetividade e a simplicidade, bem como a mobilização para transformação social. Por sua vez, essas vertentes, epistemológica e social, podem convergir para a constituição do saber ambiental na formação dos estudantes.

O contato com a comunidade foi promovido pelo mapeamento ambiental, mas a carga horária foi insuficiente para o desenvolvimento de projetos de transformação social, reduzindo essa estratégia a uma sugestão de como desenvolver programas de intervenção. Os Estudos Culturais foram mencionados pela professora como a tendência da disciplina, mas não foram incluídas como mais uma tendência para EA.

Em nossa análise, a disciplina acompanhada, apesar de não atender na íntegra os pressupostos da EA acenados em Tbilisi e presentes ainda nas orientações da área, vai além dessas orientações, quando enfoca os Estudos Culturais, enfatiza os artefatos culturais, com uma bem explorada utilização de filmes e textos bastante instigantes.

A disciplina deixou sua marca no curso de Biologia, garantindo a apresentação de uma temática que é singular e relevante na formação dos biólogos, constituindo-se como uma importante estratégia para o fortalecimento da temática no curso. Foi bem ministrada, a professora demonstrou saber de onde fala, com domínio do conteúdo e competência técnica.

Ressaltamos, por fim, a importância do projeto pedagógico na institucionalização da EA na formação inicial em Biologia. Ele reflete as condições anteriores, organiza o presente e aponta para o futuro. No curso de Ciências Biológicas da UFU, passou a vigorar um novo projeto a partir de 2006, que, no momento, está em discussão para mudanças dentro da ideia de currículo, que é dinâmica. Naquele momento, foi possível a inserção da temática na forma disciplinar, contrariando a própria natureza da EA assemelhando-se a muitos outros cursos pelo país. Agora, pensamos em disciplina interdepartamental, integração com Programas de Educação Tutorial (PET), acolhimento de alunos interessados em elaborar seus Trabalhos de Conclusão de Curso (TCC) em EA. Confirma-se, portanto, a percepção de Sorrentino (1995) em sua tese de doutorado, de que a disciplina poderia ser um lugar para aglutinar interesses pela EA.

A pesquisa realizada evidenciou que a disciplina exerce um importante papel para a institucionalização da temática no curso, porém, sinaliza também para as dificuldades e o longo caminho a ser percorrido para seus avanços e novas formas de oferta. Apesar de inscrita numa perspectiva curricular disciplinar, a presença da EA no curso demonstrou potencial para oferecer novos olhares e caminhos para a formação dos biólogos, especialmente se não abrir mão da discussão social e epistemológica priorizada pelo tema.

\section{Referências}

ANDRÉ, M. E. D. A. Estudo de caso: seu potencial na educação, Cadernos de pesquisa, São Paulo, s/v, n.49, p.51-54, Mai.1984.

BERNARDES, M. B. J.; PRIETO, E. C. Educação Ambiental: disciplina versus tema transversal, Revista Eletrônica do Mestrado em Educação Ambiental, Rio Grande/RS, v.24, p.173-185, Jan./Jul. 2010.

BITTAR, M. et. al. Educação ambiental e universidade: algumas considerações sobre a formação de professores. In: JORNADA HISTEDBR, 7, Campo Grande, 2007. Anais... Campo Grande: UNIDERP, 2007. CD ROOM. 
BRANCO, S. M. Meio Ambiente \& Biologia. São Paulo: SENAC São Paulo, 2001.

BRÜGGER, P. Educação Ambiental ou Adestramento Ambiental? 3. ed. Chapecó: Argos, 2004.

CHIZZOTTI, A. Pesquisas em Ciências Humanas e Sociais. São Paulo: Cortez, 2008.

COSTA, M. V.; SILVEIRA, R. H.; SOMER, L. H. Estudos culturais, educação e pedagogia, Revista Brasileira de Educação, Rio de Janeiro, s/v, n.23, p.36-61, Mai./Ago. 2003.

CUNHA, M. I. Paradigmas científicos e propostas curriculares, Interface, Botucatu, v.2, n.2, p.197-204, fev. 1998. Disponível em:<http://www.scielo.br/pdf/icse/v2n2/13.pdf>. Acesso em: 12 ago. 2010.

FERNANDES, E. C. Educação Ambiental nas escolas do Município de Uberlândia - MG, Brasil. 2002. 126f. Dissertação (Mestrado em Ecologia) - Universidade Federal de Uberlândia, Uberlândia, 2002.

GOERGEN, P. Teoria e ação no gt educação ambiental da ANPED: partilhando algumas suspeitas epistemológicas, Pesquisa em educação ambiental, São Carlos, v.5, n.2, p.9-30, Jul./Dez. 2010.

GONZAGA, A. M. A pesquisa em educação: um desenho metodológico centrado na abordagem qualitativa. In: PIMENTA, S. G. et al. (Orgs.) Pesquisa em Educação: Alternativas investigativas com objetos complexos. São Paulo: Loyola, 2006. p.65-92.

GUHA, R. O biólogo autoritário e a arrogância do anti-humanismo. In: DIEGUES, A. C. (Org.). Etnoconservação: novos rumos para a proteção da natureza nos trópicos. São Paulo: Anablume, 2000. p.81-100.

LEFF, E. Epistemologia Ambiental. São Paulo: Cortez, 2001.

LIMA, L. R. Estudos Culturais: propedêutica, rivalidades e perspectivas. Fólio, Vitória da Conquista,v.2, n.2, p.83-92, Jul./Dez. 2010. Disponível em: <http://periodicos.uesb.br/index.php/folio/article/viewFile/238/485>. Acesso em: 25 set. 2011.

LOUREIRO, C. F. B. Trajetória e fundamentos da Educação Ambiental. São Paulo: Cortez, 2006.

LUDKE, M.; ANDRÉ, M. Pesquisa em Educação: abordagens qualitativas. São Paulo: EPU, 1986.

MARTINS, G. A. Estudo de caso: uma estratégia de pesquisa. São Paulo: Atlas, 2008.

MASETTO, M. T. Professor universitário: um profissional da educação na atividade docente. In: ___ (Org.). Docência na Universidade. Campinas: Papirus, 1998. p.9-25.

MEYER, M. Reflexões sobre o panorama da Educação Ambiental no ensino formal. In: Panorama da Educação Ambiental no ensino fundamental. Brasília: MEC/Secretaria de Educação Fundamental, 2001. p. 89-92. 
MOREIRA, M. A. Investigação e Educação em Ciências: métodos qualitativos. Actas del PIDEC, v.4, p.25-55, 2002. Disponível em: 〈http://www.if.ufrgs.br/ moreira/pesqquali.pdf〉. Acesso em: 25 out. 2010.

PEDRINI, A. G. (Org.) Educação Ambiental: reflexões e práticas contemporâneas. Petrópolis: Vozes, 1997.

POMBO, O. Interdisciplinaridade e integração dos saberes. Liinc em Revista, Rio de Janeiro, v.1, n.1, p.3-15, Mar. 2005. Disponível em: <http://revista.ibict.br/liinc/index.php/liinc/article/viewFile/186/103>. Acesso em: 28 jul. 2011.

REDE UNIVERSITÁRIA DE PROGRAMAS DE EDUCAÇÃO AMBIENTAL (RUPEA). Mapeamento da Educação Ambiental em instituições Brasileiras de educação superior: Elementos para discussão sobre políticas públicas. 2005. Disponível em: $<$ http://portal.mec.gov.br/secad/arquivos/pdf/educacaoambiental/rel_rupea.pdf>. Acesso em: 25 fev. 2010.

REIGOTA, M. O estado da arte da pesquisa em Educação Ambiental no Brasil, Pesquisa em Educação Ambiental, São Carlos, v.2, n.1, p.33-66, Jan./Jun. 2007.

RHODES, G. M. Epistemologia Ambiental: uma abordagem filosófico-cientificista sobre a efetuação humana alopoiética. Porto Alegre: EDIPUCRS, 1996.

RODRIGUES, H. W. Educação ambiental no âmbito do ensino superior brasileiro. In: LEITE, J. R. M.; FILHO, N. B. B. (Orgs.) Direito ambiental contemporâneo. Barueri: Manole, 2004. p.395-409.

SAMPAIO, S. M. V.; WORTMANN, M. L. C. Fabricação de educadores/as ambientais e experiências: alguns olhares para a formação de professores/as. In: ENCONTROS DA ASSOCIAÇÃO NACIONAL DE PÓS-GRADUAÇÃO E PESQUISA EM AMBIENTE E SOCIEDADE, 2, Indaiatuba, 2004. São Paulo: ANPPAS, 2004. Disponível em: <http://www.anppas.org.br/encontro_anual/encontro2/GT/GT10/shaula_sampaio.pdf>. Acesso em: 4 jun. 2011.

SATO, M. Educação ambiental. São Carlos: Rima, 2003.

SORRENTINO, M. Educação Ambiental e Universidade: um estudo de caso. 1995. 263f Tese (Doutorado em Educação) - Universidade Federal de São Paulo, São Paulo, 1995.

TBILISI. Conferência Intergovernamental sobre Educação Ambiental de Tbilisi - Documento Final. URSS: UNESCO, 1977.

THOMAZ, C. E.; CAMARGO, D. M. P. Educação Ambiental no Ensino Superior: múltiplos olhares, Revista Eletrônica do Mestrado em Educação Ambiental da FURG, Rio Grande, v.18, s/n, p.303-318, Jan./Jun. 2007.

TRISTÃO, M. Educação Ambiental na formação de professores: rede de saberes. São Paulo: Annablume, 2004. 
VASCONCELOS, M. J. E. Pensamento Sistêmico: o novo paradigma da Ciência. Campinas: Papirus, 2002.

VERDI, M.; PEREIRA, G. R. A Educação Ambiental na Formação de Educadores - o caso da Universidade Regional de Blumenau - FURB.Revista Eletrônica do Mestrado em Educação Ambiental da FURG, Blumenau, v.17, s/n, p.375-391, Jul./Dez. 2006.

Versão recebida em 23/10/2014

Aceite em 16/04/2015 